\title{
WestVirginiaUniversity
}

THE RESEARCH REPOSITORY @ WVU

Graduate Theses, Dissertations, and Problem Reports

1999

\section{Association of parental weight with pregnancy weight gain and outcome}

\author{
Rini Banerji \\ West Virginia University
}

Follow this and additional works at: https://researchrepository.wvu.edu/etd

\section{Recommended Citation}

Banerji, Rini, "Association of parental weight with pregnancy weight gain and outcome" (1999). Graduate Theses, Dissertations, and Problem Reports. 1013.

https://researchrepository.wvu.edu/etd/1013

This Thesis is protected by copyright and/or related rights. It has been brought to you by the The Research Repository @ WVU with permission from the rights-holder(s). You are free to use this Thesis in any way that is permitted by the copyright and related rights legislation that applies to your use. For other uses you must obtain permission from the rights-holder(s) directly, unless additional rights are indicated by a Creative Commons license in the record and/ or on the work itself. This Thesis has been accepted for inclusion in WVU Graduate Theses, Dissertations, and Problem Reports collection by an authorized administrator of The Research Repository @ WVU. For more information, please contact researchrepository@mail.wvu.edu. 


\title{
Rini Banerji
}

Thesis submitted to the

College of Agriculture, Forestry, and Consumer Sciences

at West Virginia University

in the partial fulfillment of the requirements

for the degree of

Master of Science

In

Family and Consumer Sciences

\author{
M. Zafar A. Nomani, Ph.D., R.D., Chair \\ Hazel A. B. Hiza, Ph.D., R.D. \\ Guendoline Brown, Ph.D. \\ Bobbie Warash, Ed.D \\ Division of Family and Consumer Sciences
}

\author{
Morgantown, West Virginia \\ 1999
}

Keywords: body mass index, pregnancy weight gain, infant birth weight Copyright 1999 Rini Banerji 


\section{ABSTRACT}

\section{Association of Parental Weight with Pregnancy Weight Gain and Outcome \\ Rini Banerji}

The purpose of this study was to determine the association of paternal of paternal BMI with maternal weight gain, the birth weight of the newborn and to develop a prediction equation. This study utilized a purposive sampling technique. The participants for this study were recruited from five different WIC sites in north central West Virginia. The sample consisted of 156 participants out of which 93 completed the study.

Data was collected from the participants through direct administration of questionnaires and personal interviews. The data was analyzed using the statistical software STATISTICA version 5.5, 1999.

The findings of this study indicate that there is a linear association between fathers' BMI and pregnancy weight gain and a curvilinear relationship between mothers' pre-pregnancy BMI and pregnancy weight gain. The prediction equation is as follows:

Weight Gain $=6.38764+0.45436\left(F \_B M I\right)$
$-0.01453\left(\mathrm{M} \_ \text {BMI }\right)^{2}$
$-2.70644($ Parity $)$

This equation is significant at $p<0.001, R^{2}=0.23, n=93$

This equation may have practical application for developing strategies during pregnancy. 


\section{Acknowledgements}

First, I would like to thank God for giving me patience, endurance and hope and for not letting me give up when the going got rough.

I would like to extend my sincerest gratitude and appreciation to the members of my committee:

Dr. M. Zafar A. Nomani, advisor and chair, for always pointing me in the right direction and for helping me with his suggestions and encouragement.

Dr. Hazel Hiza, for giving me the opportunity to work on this project. This opened a lot of doors for me. Thank you Dr. Hiza for being my teacher and friend.

Dr. Guendoline Brown, for selecting me to be her graduate assistant. You made it possible for me to come this far. You were a wonderful mentor and friend.

Dr. Bobbie Warash, for taking the time to serve on my committee.

I want to thank Dr. Mary Head and Ms. Betty Forbes for all their support.

I thank my parents for their constant love and support and for their words of encouragement whenever I needed it.

I would also like to thank my sister for the numerous telephone calls that has helped me get through some of the toughest times.

To my husband Kunal, I dedicate this thesis. Thank you for always believing in me. I am grateful to you for not letting me give up hope and for always being there when I needed you. Without your love and support this would not have been possible. 


\section{TABLE OF CONTENTS}

ABSTRACT

Page

ACKNOWLEDGEMENTS iii

LIST OF TABLES vi

CHAPTER 1: INTRODUCTION - 1

Statement of the Problem-10 3

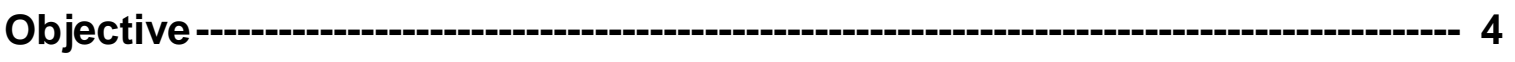

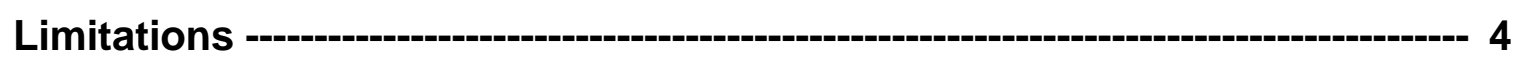

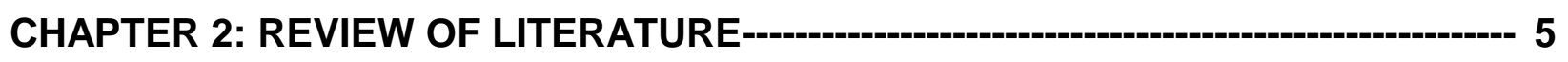

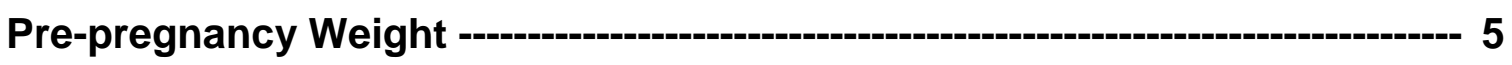

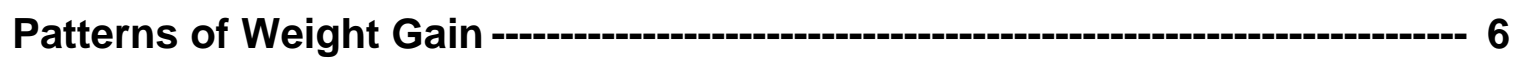

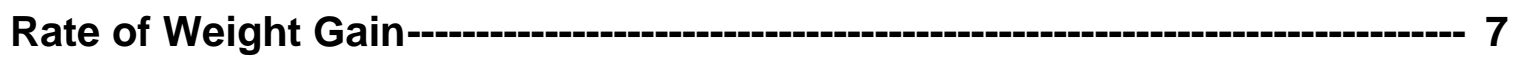

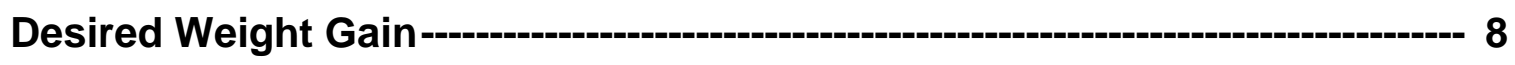

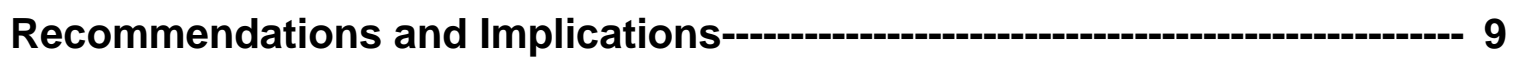

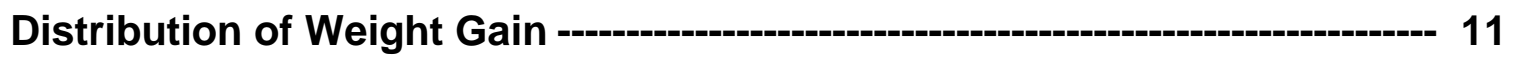

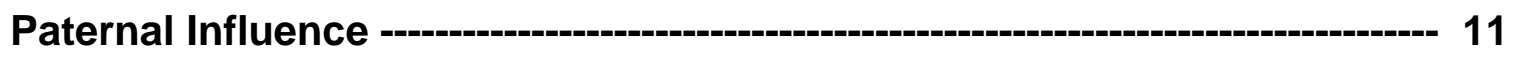

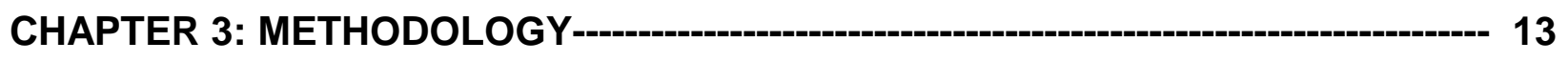

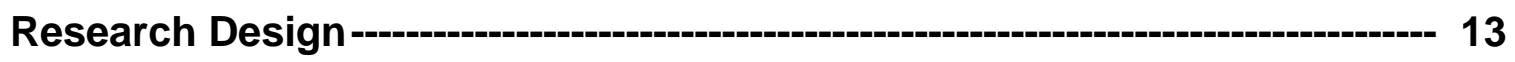

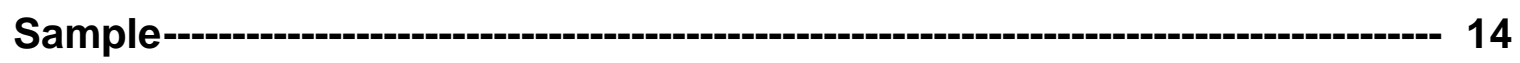

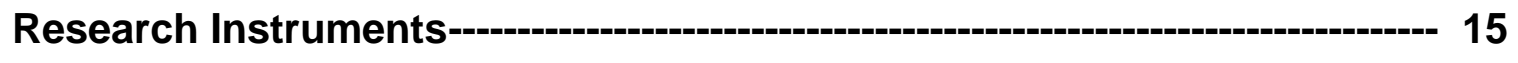

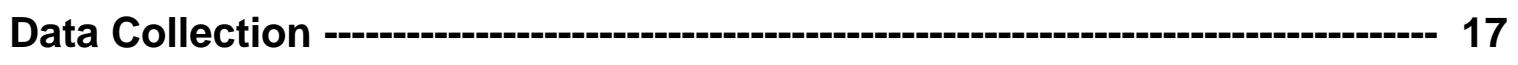

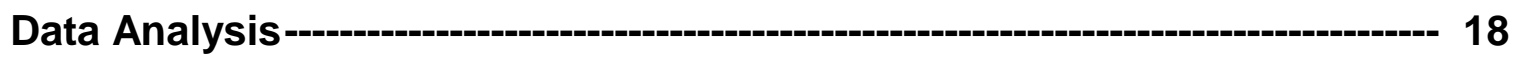




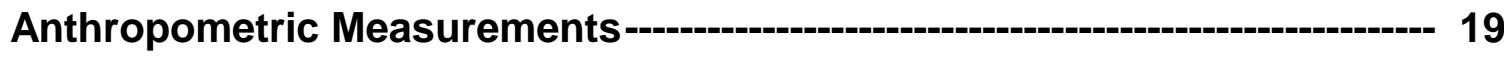

Nutrient Intake ---on

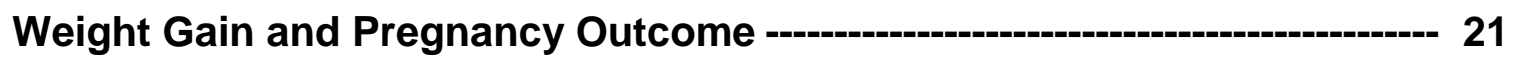

Association of Paternal and Maternal BMI and Pregnancy Weight Gain--- 22

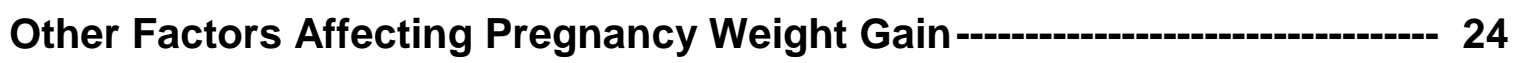

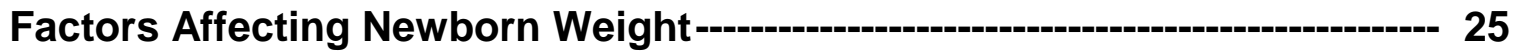

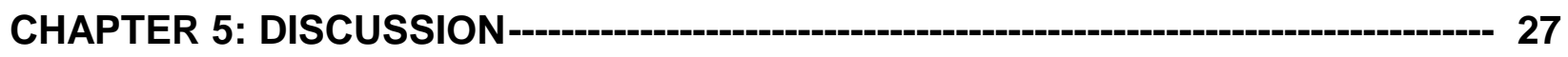

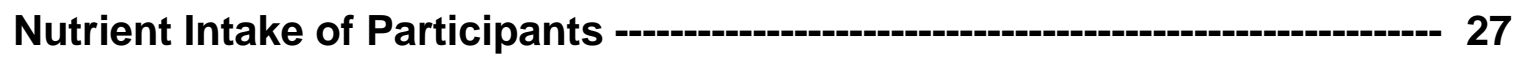

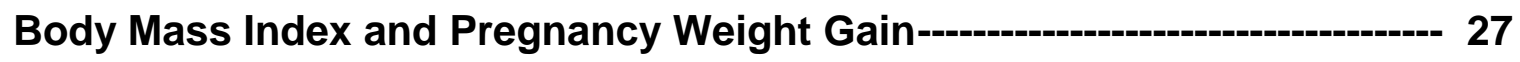

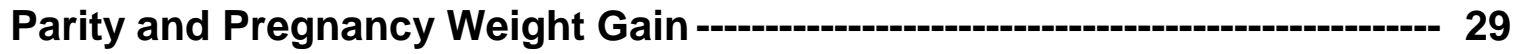

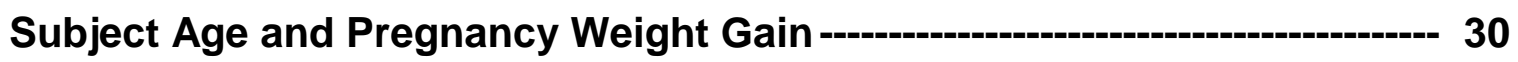

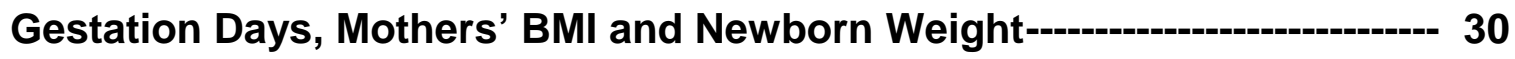

CHAPTER 6: CONCLUSION

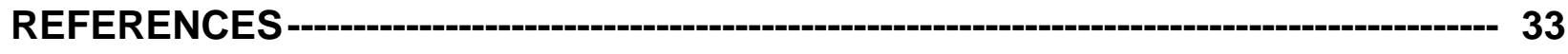

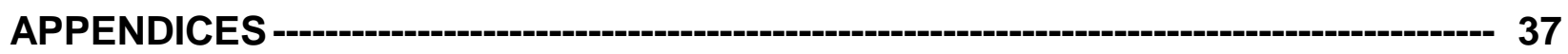

Appendix A: Special Supplemental Food Program for WIC ----a--------- 37

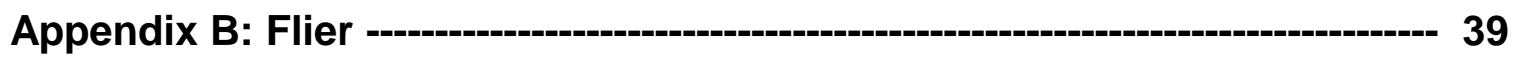

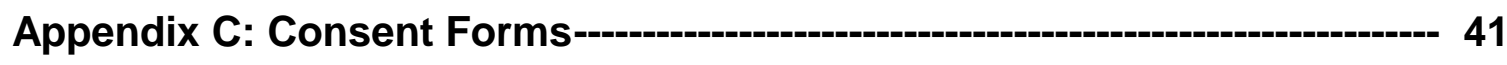

Appendix D: Weight and Blood Pressure --.-.-.-.- 47

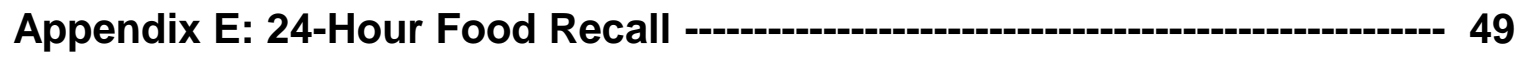

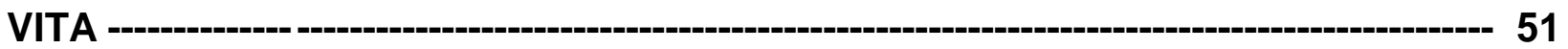




\section{LIST OF TABLES}

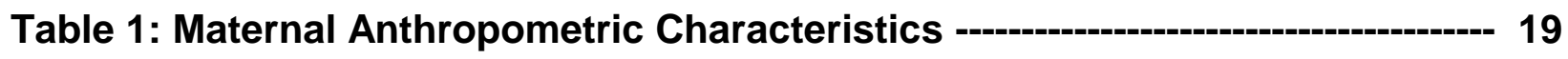

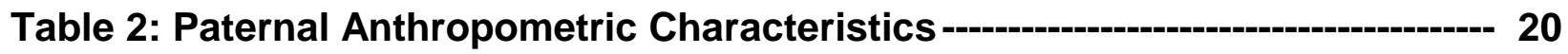

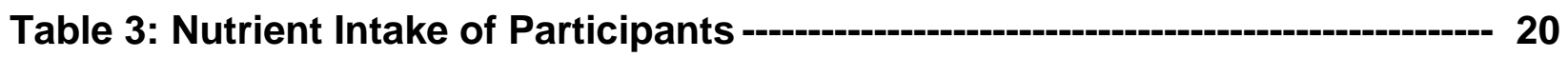

Table 4: Weight Gain, Gestation Days and Birth Weight Of Newborn-------------- 21

Table 5: The Relationship between Maternal and Paternal BMI and Pregnancy

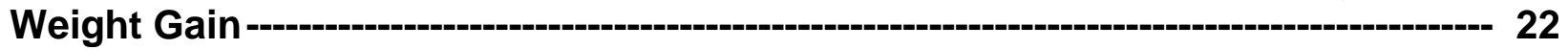

Table 6: Effect of Parental BMI Interaction on Pregnancy Weight Gain ----------- 23

Table 7: Effect of Parental BMI, Parity, and Age on Pregnancy

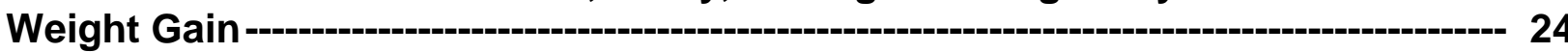

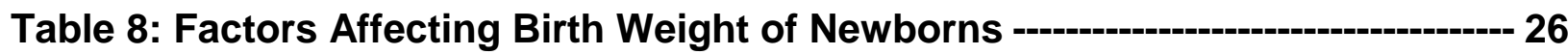




\section{CHAPTER 1}

\section{INTRODUCTION}

In the 1940s and 1950s it was believed that birth complications increased with larger babies. It was accepted practice in the United States to restrict weight gain during pregnancy to less than $9 \mathrm{kgs}$ or $20 \mathrm{lbs}$. (Reported by IOM). However, the results of the study published by Eastman and Jackson (1968), indicated that mothers who gained less than $9 \mathrm{kgs}$ during their pregnancy had smaller babies. The study showed that these babies had a very poor chance of survival. Subsequently, the Food and Nutrition Board's Committee on Maternal Nutrition reviewed all the problems, practices and research related to pregnancy weight gain, and presented a comprehensive report. This report entitled "Maternal Nutrition during the Course of Pregnancy" provided recommendations for weight gain during pregnancy. These recommendations were published in 1970 (NRC, 1970) and since then a number of studies have shown that weight gain during pregnancy depends on the pre pregnancy weight for height of the mother (Abrams and Laros 1986, Miller and Merritt, 1979). The Institute of Medicine pointed out that women with inadequate pre-pregnancy weight need to gain more weight during pregnancy than those who had more than adequate pre-pregnancy weight (IOM, 1990).

In 1971, Hytten and Leitch established physiologic norms for total weight gain, the rate of gain in the last half of pregnancy, and the rate of gain associated with the best reproductive performance. These researchers used data from two British studies, Humphreys (1954) and Thomson and Billewicz (1957), and concluded that healthy 
pregnant women in their first pregnancy, who are eating without restriction should gain 12. $5 \mathrm{kgs}$ (27.5 lbs.) during their pregnancy. This gain is approximately divided into $1 \mathrm{~kg}$ (2.2 lbs.) in the first trimester and the rest during the last two trimesters. For multigravid women they suggested a slightly lower weight gain. Recent studies have demonstrated that inadequate weight gain during the second half of pregnancy predicts adverse pregnancy outcomes.

Studies conducted by Miller and Merritt (1979), Abrams and Laros (1986) reported a relation between pre-pregnancy weight and pregnancy weight gain. The researchers reported that women who had a BMI $<19.8$ gained more than $12.5 \mathrm{~kg}$ during the pregnancy and those women with a high BMl gained less than the recommended $12.5 \mathrm{~kg}$ during their pregnancy.

In 1990, in the report entitled "Nutrition during Pregnancy" the Institute of Medicine (IOM) set forth a new weight gain recommendation for pregnant women. The report suggested the use of Body Mass Index (BMI) as the preferred method of classifying pregnant women into their pre-pregnancy weight categories. Based on their pre-pregnancy weight the women were grouped as low, moderate, high and very high BMI categories which was calculated by the formula: Pre-pregnancy body weight $(\mathrm{kg}) /$ Height $\left(\mathrm{m}^{2}\right) . \quad$ A BMI of $<19.8=$ low $19.8-26.0=$ moderate; $26.1-29.0=$ high $;>29.0$ $=$ very high. IOM based the new recommendations on scientific evidence and through observational studies that looked at the relation between pre-pregnancy weight and pregnancy weight gain to pregnancy outcomes.

In the past, the weight gain recommendation has been focused on one value (11 $\mathrm{kg}$ ) as the ideal weight gain objective. In a 1990 report released by the United States 
Food and Nutrition Board, the recommendation for weight gain during pregnancy was changed from one ideal weight gain to a range of weight gain depending on the prepregnancy BMI of the mother. The Food and Nutrition Board suggested a broad range of $6.8 \mathrm{~kg}$ to $18 \mathrm{~kg}$ weight gain depending on the group the mothers' pre-pregnancy BMI was categorized. The IOM recommends women with a low BMI that is less than 19.8 to gain 12.5 to $18 \mathrm{~kg}$. Women with normal BMl of 19.8 to 26 gain 7 to $11.5 \mathrm{~kg}$, and women with a very high BMI over 29 to gain $6.8 \mathrm{~kg}$. The $6.8-\mathrm{kg}$ is recommended to be the minimum amount of weight to be gained during pregnancy irrespective of how high the pre-pregnancy BMI is.

Weight gain during pregnancy is considered a major determinant of fetal growth (Johnston, 1991). Lower than recommended maternal weight gain is associated with higher incidences of low birth weight infants who are at an increased risk for mortality.

\section{Statement of the Problem}

Although much research has been done regarding maternal weight gain there is a distinct lack of research regarding the influence of the father on maternal weight gain and pregnancy outcome. A recent study by Albrecht \& Miller (1994) has indicated that family structure, mainly the presence or absence of the father, is an important tool in understanding birth outcomes. The major purpose of this study was to determine the effect of paternal BMI on maternal weight gain and birth weight of the newborn. The participants of this study were from five counties in north central West Virginia: Monongalia, Marion, Harrison, Preston, and Taylor. The candidates were recruited from the WIC program, which is the supplemental nutrition program for Women, Infants and Children (Appendix A). 
The results of this study might motivate other researchers to conduct in depth research on ways to improve pregnancy outcome. The results might also help the local and state authorities to design intervention and preventive programs that may lead to healthy and successful pregnancies.

\section{Objective of the Study}

The objective of the study is

To determine the association of paternal BMI with maternal weight gain, the birth weight of the newborn and to develop a prediction equation.

\section{Limitations of the Study}

A purposive sampling technique was used to collect the data. Purposive sampling technique is a probability sampling in which subjects are judged to be representative or typical of the chosen population (Ary and Razavieh, 1996). Due to legal restrictions the researchers had to obtain informed consent from the participants. This purposive sampling limited an accurate representation of the target population.

The data for this study were obtained by survey method. Information regarding the participants' pre-pregnancy weight, the weight and height of the father were self reported and could not be verified for accuracy.

Another limitation of this study was the relative high attrition rate among the participants. Out of the original 156 participants there was $71 \%$ participation and $29 \%$ attrition. This high attrition rate may have been caused by various factors. The participants of this study were offered a cash incentive, therefore, as soon as they received a part of the incentive money some would lose interest in the study. The other reasons may have been lack of transportation, limited education, and lack of interest. 


\section{CHAPTER 2}

\section{REVIEW OF LITERATURE}

The purpose of this study was to determine the association of parental weight (both mother and father) to maternal weight gain during pregnancy and birth weight of the newborn. According to the study by Johnston (1991), weight gain during pregnancy is considered a major determinant of fetal growth and lower than recommended weight gain, especially during the second half of pregnancy may be a predictor of adverse pregnancy outcome. Recent studies have also highlighted the importance of family structure in understanding birth outcomes (Albrecht and Miller, 1994). However, there is a lack of information regarding the influence of the father on maternal weight gain and pregnancy outcome.

The following review of literature addresses various aspects and determinants of maternal weight gain and pregnancy outcome. This section deals with pre-pregnancy weight of the mother and its impact on pregnancy outcome, the patterns of weight gain during pregnancy, rate of maternal weight gain, desired weight gain, recommendations and implications of adequate weight gain during pregnancy, paternal influence on weight gain during pregnancy and pregnancy outcome.

\section{Pre-pregnancy Weight}

Lumme and Rantakallio (1995), conducted a study in Northern Finland with a sample size of 9015 women and reached the conclusion that pre-pregnancy obesity was associated with an elevated risk of hypertension and diabetes during pregnancy and was also responsible for larger for gestational age babies. Another study conducted by Cnattingius et al (1998) in Sweden, with a sample size of 167,750 women looked at 
the relationship between pre-pregnancy weight of the mother and the frequency of late fetal death, early neonatal death, pre-term delivery and delivery of a small for gestational age infant. This study concluded that high pre-pregnancy weight of the mother is positively associated with the risk of late fetal death. Both of these studies indicate that the pre-pregnancy weight of the mother is an important precursor to having a healthy baby.

\section{Patterns of Weight Gain}

There was a wide variation in the pattern of weight gain during pregnancy. According to Dawes and Grudzinskas (1991) who did a retrospective study of 1145 pregnant women, the mean weight gain of heavy women $(>68 \mathrm{Kg})$ and light women $(<55.4 \mathrm{Kg})$ were less than those women whose weight was between $60-68 \mathrm{~kg}$. The other interesting variation was young women ( $<20 \mathrm{yr}$.) who gained less weight up to 37 weeks of pregnancy than women who were over 25 years old, but after 37 weeks this trend was reversed. It was further noticed that primi gravid (pregnant for the first time) women gained more weight after 37 weeks than parous (previously borne offspring) women.

The pattern of pregnancy weight gain also varied with the trimester. The average rate of weight gain was lowest in the first trimester, peaked during the second trimester and decreased slightly during the third trimester. According to Abrams et al (1995) the most important determinant of weight gain per trimester were age and ethnicity in the first trimester, pre-pregnancy BMI, parity, and height in the second trimester and hypertension, age and parity in the third trimester. Parity is defined as the number of 
pregnancies the woman has had that has resulted in the birth of an infant capable of survival.

Another study by Siega-Riz and Adair (1993) in Filipino population, predicted that first trimester weight gain was highest amongst women who had higher parity, among those women who had a low pre-pregnancy BMI and those women who had a longer interval between pregnancies. Total weight gain was high among women with low prepregnancy BMI, among those who had longer intervals between pregnancies, tall women and those who had excess energy intakes. Age seemed to be negatively related to total weight gain during pregnancy. Pregnant women over the age of 35 years seemed to gain less weight than pregnant women who were younger.

\section{Rate of Weight Gain}

According to the following research studies the rate of weight gain during pregnancy is a significant indicator of pregnancy outcome. According to Witwer (1990) lower than normal weight gain during the second half of pregnancy is strongly related to spontaneous delivery before 37 weeks' gestation among both teenagers and older

women. According to Abrams et al (1989) and Hediger et al (1989) weight gain during the second trimester of pregnancy is most crucial. Insufficient weight gain or low rate of weight gained during the second trimester, especially after the $20^{\text {th }}$ week of gestation increases the incidences of pre-term delivery by more than $60 \%$. This is true even for those individuals who gained an adequate amount of weight overall. The studies also found that an inadequate weight gain either early or late in pregnancy increased the risk of delivering a low birth weight infant. 
Johnston et al (1992) supports the conclusions inferred by Abrams et al (1989) and Hediger et al (1989). The results of these studies suggest that good pregnancy outcome is based on infant birth weight and that maternal weight gain can be influenced to promote good pregnancy outcome.

\section{Desired Weight Gain}

According to the American College of Obstetricians and Gynecologists (ACOG) a total weight gain of $10-12 \mathrm{~kg}$ was considered as "generally acceptable." A weight gain of less than $1 \mathrm{~kg} /$ month in the second and third trimester was considered as inadequate and a weight gain of more than $3 \mathrm{~kg} /$ month were considered as excessive weight gain. However, recently published studies (Abrams and Parker, 1990) report that the mean maternal weight gain is higher than the recommended range and they are associated with good pregnancy outcome. Therefore, Abrams and Parker (1990) suggested that the limits of a recommended weight gain range should include the amount of weight gain that is both associated with good pregnancy outcome and experienced by the majority of pregnant women to whom it will be applied. They also suggested that to be useful for individual women, maternal weight gain recommendation should reflect maternal characteristics such as pre-pregnancy weight for height, age, race and parity. Abrams and Parker (1990) defined good pregnancy outcome as a vaginal birth between 37-42 weeks of gestation of a living, singleton infant of appropriate birth weight for gestational age without congenital anomalies, born to a mother who did not experience diabetes or hypertension during pregnancy. The researchers studied a cohort of 4,674 women and found that more than seventy five percent of the women gained more than 
$12 \mathrm{~kg}$ and still experienced a good pregnancy outcome. Eighty percent of the cohort gained weight in the range of $10-21 \mathrm{~kg}$.

The result of this study indicates that the association between maternal weight gain and the birth weight of the infant is less important for those women who were categorized as over weight and obese before their pregnancies. This study concludes that although the lower limit of the recommended range of maternal weight gain is relevant the upper limit needs to be more flexible depending on the pre-pregnancy weight of the individual.

Ratner et al (1990) supported the conclusion drawn by Abrams et al concerning pregnancy weight gain. Ratner and colleagues agreed that the amount of weight gained by an individual during pregnancy should depend upon the pre-pregnancy weight of the mother. The study conducted by these researchers looked at the effect of gestational weight gain in extremely obese women and recommended that less than the suggested weight gain in morbidly obese women does not adversely affect fetal outcomes. Therefore, it is desirable that morbidly obese women gain less than the recommended weight during pregnancy.

\section{Recommendations and Implication of Adequate Weight Gain}

According to the 1990 report released by the United States Food and Nutrition Board, the recommended pregnancy weight gain for women with a low BMI is 12.5 to $18 \mathrm{~kg}$; for women with normal BMI is $7 \mathrm{~kg}$ to $11.5 \mathrm{~kg}$ and for women with high BMI is 6.8 $\mathrm{kg}$. The $6.8 \mathrm{~kg}$ is the minimum amount of weight that pregnant women should gain irrespective of how high the pre-pregnancy BMI is. Siega-Riz et al (1994) noted that weight monitoring during pregnancy was an important tool for predicting pre-term birth. 
Siega-Riz and others based their observation in a predominantly Hispanic population and concluded that a weight gain of less than $90 \%$ of the IOM recommendation in the third trimester may serve as an indicator for identifying women at risk of delivering preterm.

Johnson et al (1992) suggested that excessive weight gain during pregnancy causes higher frequencies of larger than normal babies that leads to increased rate of cesarean section and other major maternal and fetal complications.

Adequate weight gain is one of the most important criteria for a good pregnancy outcome. The reason for recommended weight gain during pregnancy was based on providing adequate nutrition to the fetus to ensure normal growth and development (Ratner et al, 1990). The determinants of weight gain are pre-pregnancy weight, parity, gestational duration and mothers' height (Siega-Riz et al, 1994). However, these variables account for a small amount of variance and leaves many of the predictors of weight gain unknown. There is a lack of information on paternal influence on pregnancy weight gain and outcome. This present study aimed to fill this void in information. In this study the weight and height of the father was considered along with height and weight of the mother in determining pregnancy weight gain and outcome. 


\section{Distribution of Pregnancy Weight Gain}

$\begin{array}{ll}\text { Fetus } & 7.5 \mathrm{lbs} \\ \text { Placenta } & 1.5 \mathrm{lbs} \\ \text { Amniotic Fluid } & 2.0 \mathrm{lbs} \\ \text { Uterus } & 2.0 \mathrm{lbs} \\ \text { Breasts } & 1.0 \mathrm{lbs} \\ \text { Blood } & 3.0 \mathrm{lbs} \\ \text { Water } & 3.5 \mathrm{lbs} \\ \text { Fat } & 7.5 \mathrm{lbs}\end{array}$

\section{Paternal Influence}

Although the above review of literature dealt with the determinants of maternal weight gain, the influence of the baby's father was not discussed. However, the limited information available indicates that the father plays an important role in making crucial decisions (Albrecht and Miller, 1994). The attitude of the expectant father influences the breast feeding choice of the mother (Carey and Weiss, 1992). Research on family structure has found that "increasing the proportion of unmarried mothers by one standard deviation implied an increase in infant deaths of 21-24\%" (Eberstein et al, 1990). Another study by Gee et al (1976) found that next to birth weight, legitimacy status was the most important factor associated with neonatal mortality.

The review of literature indicated that weight gain during pregnancy was a serious indicator of good pregnancy outcomes, and the amount of weight gained was 
determined by a number of different factors. Some of the important factors were prepregnancy BMI of the mother, age, parity and gestation days. There was no information on the influence of the father on weight gain. Hopefully, this study will provide some information on the influence of fathers on good pregnancy outcomes. 


\section{CHAPTER 3}

\section{METHODOLOGY}

The objective of this study was to examine the association of parental weight with pregnancy weight gain and optimal birth weight of the new born amongst the WIC program participants residing in north central West Virginia. Optimal birth weight was defined in this study as a new born whose birth weight was greater than 2500 grams and less than 4500 grams and who was born without any genetic anomalies.

\section{Research Design}

The research design for this study was twofold: a prospective observational approach for the collection of primary data; and a retrospective study based in large part on secondary data. The prospective observational design involved the recruitment of pregnant women either in their first, second or third trimester of gestation and following them throughout the remainder of pregnancies until delivery. The information obtained from the participants included socio-demographic data, anthropometric data of both the mother and the father, weight changes during pregnancy, pregnancy history, pregnancy outcome and postnatal information. This information was obtained through one on one interviews and direct administration of questionnaires. The retrospective data were obtained from the participants' prenatal records and the infants' birth certificates.

The dependent variables for this study were pregnancy weight gain, and infant birth weight. The independent variables were pre-pregnancy BMI of the mother, the paternal BMI and days of gestation. 
The study was carried out in four phases, with each successive phase building upon the previous one. Phase I involved the recruitment, training and monitoring of staff; recruitment of participants and baseline data collection. Phase II was an extension of Phase I with continued recruitment of participants, training and monitoring of staff, refinement of data collection techniques, coding, data processing and analysis. Phase III involved data collection and coding, data analysis and preliminary compilation of results and proposal preparation for external findings. Phase IV was used to complete data analysis and final preparation of reports.

\section{Sample}

Purposive sampling technique was used in this study. The goal of this type of sampling was to select cases that were likely to be information rich with respect to the purpose of the study (Gall, Borg and Gall 1996 p, 218). The sample for this study consisted of pregnant women from Monongalia, Marion, Harrison, Preston and Taylor counties in West Virginia. The participants were recruited from the government agencies that provide special supplemental food programs for women, infants and children (WIC).

A total of 156 participants were recruited from the five WIC sites at the previously mentioned counties. The participants were either in their first, second or third trimester of gestation. Out of the 156 participants, 93 subjects had complete sets of data for BMI, gestation days and weight gain. The difference in the sample size was due to attrition, obscure responses by the participants and incomplete entry of data. The participants represented a wide range of age, race, religion and ethnic background. 
There were 141 participants who were white non-Hispanic, 11 were black non-Hispanic, 2 were Hispanic and 2 were of other race.

\section{Research Instruments}

Relevant information for the study was obtained from the participants by the survey method. Survey method is used to describe research that involves administering questionnaires and interviews. The purpose of the survey was to collect data from the participants in order to generalize the findings to a population that the sample was intended to represent (Gall, Borg and Gall 1996 p, 289). A combination of interviews and questionnaires were utilized to obtain information for this study. The primary advantages of the direct administration of the questionnaires were the higher response rate as well as the cost effectiveness. The disadvantages were they could not probe too deeply. On the other hand, the major advantages of the interview process were the ability of the trained interviewers to obtain more information and clarify obscure statements.

The research instruments consisted of survey questionnaires. Trained research assistants directly administered the instruments to the participants. The data collection process was performed either at the participants' home, WIC sites or the Family and Consumer Sciences office at West Virginia University. The venue depended upon the convenience of the participants.

The instruments utilized for the purpose of this study were as follows:

Personal information (Questionnaire \# 5); consisted of socio demographic information such as, age, race, marital status, education level, occupation, household income and 
information pertaining to the child's father. The information regarding the age and race of the mother was considered for this study.

Anthropometric data (Questionnaire \# 10); was adopted to gather data regarding height and weight of the father as well as height and pre-pregnancy weight of the participant. This instrument also contained the weight of the participant at her first prenatal visit.

Maternal Medical Information (Questionnaire \# 11); used to calculate the current gestation period. This instrument dealt with information such as, last menstrual period, due date, medical information related to current pregnancy. The obstetricians determined the gestation days of the babies using one of three different methods

1) If the mother had a regular 28 days menstrual cycle then the gestation days was calculated by taking the first day of the last menstrual cycle and adding 7 days to it. To this number 9 months was added and this was considered to be the expected date of delivery.

2) The second method was adding 40 weeks to the first day of the last menstrual period and this was the expected date of delivery. This method was used only if the mother had regular menstrual cycles.

3) If the mother did not have regular menstrual cycles then the doctor performed an ultra sound on the mother, in the office, to determine the expected date of delivery.

The weight gain and blood pressure measurements were obtained from the participant's medical records from each prenatal visit. The nurses at the doctors' office recorded the weights of the participants using a standing scale. Weights were taken 
from the participants while fully clothed and with shoes on. Jackets and heavy coats had to be taken off before the participants were weighed.

The daily nutrient intake of the participants was assessed by taking 24-hour food recalls. A minimum of three 24 -hour food recalls were collected from each participants during the time they were involved in the study. Some participants filled out more than three 24-hour recalls depending upon when they joined the study. The average nutrient intake of the participants were analyzed using the Nutritionist IV software.

Reproductive History (Questionnaire \# 14); provided information on parity, age of the participant at first pregnancy, abortions, miscarriages and still births experienced by the participants. This also provided data on previous pregnancy outcomes related to birth weight of the infant.

The postnatal and infant questionnaires (\#17 \& 18) provided data on delivery date, type of delivery, complications before, during and after delivery, the weight, length and head circumference of the newborn, gender and any complication or anomaly present in the infant.

All of the above survey instruments were components of the research study entitled Factors Affecting Perinatal, Maternal, Nutrition Status, Health and Pregnancy Outcomes.

\section{Data Collection}

February 271997 was the date for the first initial data collection and the study continued until December 1998. The participants for the study were recruited through posting fliers (Appendix B) in the WIC sites as well as through radio announcements and advertisements in the local newspapers. However, the majority of the recruitment 
was done by the research assistants at the WIC sites. Interested individuals were later contacted by phone to set up time and place for the interview. At the initial meeting the participants were required to sign an informed consent form previously approved by the West Virginia University Institutional Review Board (IRB) for the Protection of Human Subjects. The data were then collected from the participants through direct administration of the instruments and personal interviews. Most of the questionnaires were administered at the initial meeting except, the weight, blood pressure, postnatal and the infant questionnaires. The weight and blood pressure information were obtained from the medical records at each prenatal visit and the remaining questionnaires were administered at a follow up session after the baby was born. The participants were offered a cash remuneration for their time and inconveniences, the amount of which varied depending upon the length of gestation at which the participant joined the study. An individual who joined in the first or second trimester was offered $\$ 50$ and those who joined in the third trimester was offered $\$ 35$ after the participant had completed the study.

\section{Data Analysis}

The data were analyzed using the statistical software package STATISTICA, version 5.5, 1999. Mean, standard deviation, simple and multiple regression as well as

multivariate analysis was done to establish correlation between variables. The significance level was set at 0.05 for all inferential statistics. 


\section{CHAPTER 4}

\section{RESULTS}

The first part of this chapter deals with descriptive information regarding the participants and father of the newborns. The descriptive statistics are presented in Table 1 and Table 2. Information pertaining to nutrient intake by the participants is presented in Table 3. The second part of this chapter deals with weight gain and pregnancy outcome.

\section{DESCRIPTIVE STATISTICS}

\section{Anthropometric Measurements}

The anthropometric measurements of the participants such as the weight, height, BMI along with the subjects' age are presented in Table 1.

Table 1. Maternal Anthropometric Characteristics

\begin{tabular}{|l|l|l|}
\hline & Mean & Standard Deviation \\
\hline Participants' Age (years) & 26.13 & \pm 5.05 \\
\hline Pre-pregnancy Wt (kg) & 67.72 & \pm 16.62 \\
\hline Participants' Height (m) & 1.64 & \pm 0.07 \\
\hline Participants BMI & 25.08 & \pm 5.79 \\
\hline
\end{tabular}

$\mathrm{N}=93$

There were 93 participants who had complete data regarding age, pre-pregnancy weight and height. The BMI of each participant was calculated using the formula $\mathrm{BMI}=$ weight $(\mathrm{kg}) /$ height $\left(\mathrm{m}^{2}\right)$. The mean age of the participants was 26.13 years and the mean BMI was 25.08 .

The anthropometric measurements of fathers are represented in Table 2. 
Table 2. Paternal Anthropometric Characteristics

\begin{tabular}{|l|l|l|}
\hline & Mean & Standard Deviation \\
\hline Fathers' Weight $(\mathrm{kg})$ & 83.83 & \pm 14.96 \\
\hline Fathers' Height $(\mathrm{m})$ & 1.80 & \pm 0.07 \\
\hline Fathers' BMI & 25.87 & \pm 17.37 \\
\hline
\end{tabular}

$\mathrm{N}=93$

The BMI of each father was calculated using the above mentioned formula and the mean BMI was found to be 25.87 .

\section{Nutrient Intake}

The average daily nutrient intakes of the participants were determined using 24hour food recalls. The energy and macronutrient intakes were analyzed using Nutritionist IV software. The macronutrients included carbohydrates, protein and fat. The average energy and macronutrient intakes of the participants are presented in Table 3.

Table 3: Nutrient Intake of Participants

\begin{tabular}{|l|l|l|}
\hline & Mean & Standard Deviation \\
\hline Energy intake (kcal) & 2246.84 & \pm 605.04 \\
\hline Protein intake (gm) & 84.61 & \pm 23.80 \\
\hline Carbohydrate intake (gm) & 312.27 & \pm 97.79 \\
\hline Fat intake (gm) & 77.67 & \pm 26.16 \\
\hline
\end{tabular}

$\mathrm{N}=93$

The participants had a mean energy intake of 2246.84 kilocalories. The mean protein intake was 84.61 grams, the mean carbohydrate intake of the participants was 
312.27 grams and the mean fat intake was 77.67 grams. The results indicated that on an average the participants' obtained $55 \%$ of the calorie from carbohydrate, $15 \%$ from protein and $30 \%$ from fat. None of the participants were taking any kind of restricted diets.

\section{WEIGHT GAIN AND PREGNANCY OUTCOME}

Out of the 93 participants $65 \%$ indicated they were primiparous or pregnant for the first time. All of the 93 participants delivered optimal birth weight newborns that is, all of the newborns weighed in the range of 2500 grams to 4500 grams. The average weight gain of the participants, the average period of gestation and the mean weight of newborns are given in Table 4

Table 4: Weight Gain, Gestation Days and Birth Weight of Newborn

\begin{tabular}{|l|l|l|}
\hline & Mean & Standard Deviation \\
\hline Gestation days & 274.56 & \pm 11.70 \\
\hline Pregnancy Weight Gain $(\mathrm{kg})$ & 15.61 & \pm 6.27 \\
\hline Weight of Newborn $(\mathrm{kg})$ & 3.46 & \pm 0.43 \\
\hline
\end{tabular}

$\mathrm{N}=93$

The mean weight gain of the participants was $15.61 \mathrm{~kg}$. The Institute of Medicine recommends a minimum weight gain of $6.8 \mathrm{~kg}$ during pregnancy and the result show that the pregnancy weight gain of the participants was very much above the recommended minimum. The mean gestation period was found to be 274.56 days. The mean weight of newborn was $3.46 \mathrm{~kg}$, which was within the range of optimal birth weight. 
The objective of this study was to determine the association of paternal BMI with maternal weight gain and to the birth weight of the newborn. Keeping this in view, the analysis is presented in two sections. Section A deals with the association of paternal BMI with maternal weight gain and section B deals with pregnancy weight gain and birth weight of newborns.

\section{A: Association with Paternal and Maternal BMI and Pregnancy Weight Gain}

A simple regression model was run to determine if any association existed between the $\mathrm{BMI}$ of the father $\left(\mathrm{F} \_\mathrm{BMI}\right)$ and mother (M_BMI) and also to determine the association of parental BMI with pregnancy weight gain, $\mathrm{kg}$. Table 5 represents the result of the simple regression.

Table 5: The Relationship between Maternal and Paternal BMI and their Association with Pregnancy Weight Gain

\begin{tabular}{|l|l|l|}
\hline & Mothers' BMI & Weight Gain kg \\
\hline Father's BMI & $0.18, n=93, p=0.08$ & $0.262, n=93, p=0.011$ \\
\hline Mothers' BMI & & $-0.292, n=93, p=0.004$ \\
\hline
\end{tabular}

The result of the simple regression indicated that with 93 subjects the association between mother and fathers' BMI was significant at $p<0.084$, however, when all the participants were considered the association was significant at $p<0.04$, $R=0.173, n=153$. This suggests that the mother and father influence each other's BMI. This simple regression analysis also indicates that weight gain during pregnancy was negatively related to the pre-pregnancy BMI of the mother. The higher the prepregnancy BMI the lower the weight gain during pregnancy. The association between 
the mothers' BMI and pregnancy weight gain was significant at $p<0.005, n=93$. There was positive association between the fathers' BMI and pregnancy weight gain. This association was significant at $p<0.01, n=93$.

The simple regression analysis indicated that there was an association between the mother and the fathers' BMI. Keeping that in view, a multiple regression stepwise forward model was set up to include the interaction between the mother and fathers' BMI on pregnancy weight gain. In this model the independent variables were Fathers' BMI (F_BMI), mothers' BMI (M_BMI), mothers' BMI square (M_BMISQ) and interaction of mother and father's BMI (MBMIxFBMI). The dependent variable was total weight gain, kg (TGAIN_KG). The summary of this model is illustrated in table 6 .

Table 6: Effect of Parental BMI Interaction on Pregnancy Weight Gain

\begin{tabular}{|l|l|l|l|l|l|}
\hline Variable & Multiple R & $\begin{array}{l}\text { Multiple R- } \\
\text { square }\end{array}$ & $\begin{array}{l}\text { R-square } \\
\text { change }\end{array}$ & F-to entr/rem & p-level \\
\hline M_BMISQ & 0.303 & 0.092 & 0.092 & 9.18 & 0.003 \\
\hline F_BMI & 0.436 & 0.19 & 0.098 & 10.90 & 0.001 \\
\hline MBMIxFBMI & 0.449 & 0.202 & 0.012 & 1.35 & 0.249 \\
\hline
\end{tabular}

The stepwise model indicated that mothers' BMI square and fathers' BMI is significantly associated with pregnancy weight gain. In this model the interaction of the mother and the fathers' $\mathrm{BMI}$ is associated with pregnancy weight gain at $\mathrm{p}<0.25, \mathrm{R}^{2}$ $=0.202$. But in the standard multiple regression model with the same dependent and independent variables the fathers' BMI, mothers' BMI, mothers' BMI square and the interaction of father and mothers' BMI were significant contributing factors in explaining 
the variance in pregnancy weight gain. An equation was developed with these contributing factors to predict weight gain.

Weight Gain = -14.9632+1.4705 (F_BMI)+0.7733 (M_BMI)-0.0046 (M_BMISQ)0.0364 (MBMIxFBMI)

$p<0.0003, R^{2}=0.206, n=93$

\section{Other Factors affecting pregnancy weight gain}

To determine other factors affecting pregnancy weight gain, various multiple regression models were analyzed. In the first model the independent variables were; mothers' BMI (M_BMI), mothers' BMI square (M_BMISQ), fathers' BMI (F_BMI), parity (first pregnancy as 1 and multiple pregnancy as 2), age of the subjects, years (SUBJ_AGE), gestation days (GESDAYS) and gestation days square (GESDAYSQ). The dependent variable was total weight in kilograms.

Table 7 represents the summary of stepwise multiple regression.

Table 7: Effect of Parental BMI, Parity and Age on Pregnancy Weight Gain

\begin{tabular}{|l|l|l|l|l|}
\hline & $\begin{array}{l}\text { Multiple R- } \\
\text { square }\end{array}$ & $\begin{array}{l}\text { R-square } \\
\text { change }\end{array}$ & F- to entr/ rem & p-level \\
\hline M_BMISQ & 0.092 & 0.0912 & 9.18 & 0.003 \\
\hline F_BMI & 0.19 & 0.098 & 10.90 & 0.001 \\
\hline PARITY & 0.227 & 0.037 & 4.29 & 0.041 \\
\hline SUBJ_AGE & 0.238 & 0.011 & 1.25 & 0.267 \\
\hline
\end{tabular}

The stepwise forward multiple regression analysis suggested mothers' BMI square, fathers' BMI and parity were significant factors in determining pregnancy weight 
gain. All the other variables were deleted for not being significant. This multiple regression analysis was significant at $p<0.05, n=93$. The $R^{2}=0.23$. As indicated in this model, the age of the subject and gestation days does not seem to be a significant factor in determining pregnancy weight gain.

As mother and fathers' BMI and parity were significant contributing factors in explaining the variance in pregnancy weight gain, a regression equation was developed using multiple regression standard model to predict weight gain. The equation is as follows:

$$
\begin{aligned}
& \text { Weight Gain }=6.38764+0.45436\left(F_{-} B M I\right)+0.46060 \text { (M_BMI) }-0.01453 \\
& \left(M \_B M I\right){ }^{2}-2.70644 \text { (Parity) } \\
& p<0.001, R^{2}=0.23, n=93
\end{aligned}
$$

\section{B. Factors Affecting Newborn Weight}

To determine the factors affecting the optimal birth weight of the newborn a forward stepwise multiple regression model was used. The independent variables for this model were subject age (SUBJ_AGE), fathers' BMI (F_BMI), mothers' BMI (M_BMI), mothers' BMI square (M_BMISQ), parity, gestation days (GESDAYS) and gestation days square (GESDAYSQ) and the dependent variable was newborn weight, $\mathrm{kg}$ (NB_WT_KG). The summary of the forward stepwise multiple regression is given in Table 8. 
Table 8: Factors Affecting Birth Weight Of Newborns

\begin{tabular}{|l|l|l|l|l|}
\hline & $\begin{array}{l}\text { Multiple R- } \\
\text { square }\end{array}$ & $\begin{array}{l}\text { R-square } \\
\text { change }\end{array}$ & F- to entr/rem & p-level \\
\hline GESDAYS & 0.116 & 0.116 & 11.94 & 0.001 \\
\hline M_BMI & 0.155 & 0.039 & 4.16 & 0.044 \\
\hline PARITY & 0.175 & 0.02 & 2.19 & 0.142 \\
\hline
\end{tabular}

The multiple regression analysis suggested that gestation days and mothers' pre-pregnancy BMI were significant factors in explaining the variance in the birth weight of newborns. The gestation days and M_BMI were significant at $p<0.05$. The $r^{2}$ for the whole model was $0.175, n=93$. According to this regression model subject age, fathers' BMI, mother's BMI square and gestation days square do not affect the birth weight of newborns. 


\section{CHAPTER 5}

\section{DISCUSSION}

This study examined the association of paternal BMI with maternal weight gain and the birth weight of newborns and found an association between mother and fathers' BMI. It also suggested that fathers' BMI was a significant factor in determining pregnancy weight gain. However, fathers' BMI was not a significant factor in explaining the variance in the birth weight of newborns.

\section{Nutrient Intake of Participants}

As stated earlier, the participants for this study were recruited from WIC sites. In the WIC program, participants receive constant nutrition education for better dietary practices. They also receive supplemental foods that are approved by the United States Department Of Agriculture (USDA). Due to these conditions there were no significant association noted with energy intake, carbohydrate, fat and protein with pregnancy weight gain. Therefore nutrient intake was not considered in the regression models.

\section{Body Mass Index and Pregnancy Weight Gain}

The result of simple regression (Table 5) indicated that the mother and father influenced each other's BMI. The analysis also pointed out that there was positive association between the fathers' BMI and pregnancy weight gain.

The review of literature indicated insufficient information regarding the influence of father on mothers' BMI. However, Albrecht and Miller (1994) suggested that the presence or absence of the father played an important role in determining good 
pregnancy outcome. More studies need to be done to determine the association between parental BMI.

The simple regression model indicated that weight gain during pregnancy was negatively related to the pre-pregnancy BMI of the mother. This result is similar to the findings of the 1993 study by Siega-Riz and Adair $(n=1367)$. The results of their study indicated that higher pre-pregnancy weight gain especially in the first trimester was associated with lower pre-pregnancy BMI. Lumme and Rantakallio (1995) also noted that maternal weight gain for the women who delivered after the $36^{\text {th }}$ week of gestation had a negative correlation with BMI.

However, the multiple regression model in this study (Table 7) with (M_BMI) ${ }^{2}$ and $\mathrm{F} \_\mathrm{BMI}$ as the independent variables indicated a curvilinear response between the prepregnancy BMI of mother and pregnancy weight gain. A previous study by Abrams and associates (1990) suggested similar findings. Abrams and colleagues classified the pregnant women as underweight, normal weight, overweight and very overweight based on their pre-pregnancy BMI. The researchers analyzed their data using analysis of variance (ANOVA). Their results indicated a curvilinear response between prepregnancy BMI of mother and pregnancy weight gain. The underweight participants in their study gained a mean weight of $14.61 \mathrm{~kg}$, normal weight women gained a mean weight of $15.26 \mathrm{~kg}$, over weight individuals gained a mean of $15.36 \mathrm{~kg}$ and the very over weights gained a mean of $13.25 \mathrm{~kg}$. This finding confirms the curvilinear response between pre-pregnancy BMI and pregnancy weight gain.

The above findings are in accordance with the 1990 recommendations by the Institute of Medicine (IOM). According to IOM guidelines women with low pre-pregnancy 
BMI $(<19.8)$ should gain more weight during pregnancy than those women with high pre-pregnancy BMI (>29.0).

The above results indicate that pre-pregnancy BMI is a good indicator of pregnancy weight gain. However, several studies have reported that high BMI women tend to underestimate their pre-pregnancy weight and low BMI women tend to overestimate their pre-pregnancy weight, but this reporting error was not too large (Carmichael et al, 1997). Since the pre-pregnancy weight for this study were also self reported by the participants, it might be assumed that there was some amount of reporting error.

\section{Parity and Pregnancy Weight Gain}

About $66 \%$ of the 93 participants in this study were primiparous or it was their first pregnancy. Parity was found to be a significant factor in determining pregnancy weight gain. Parity was found to be negatively related to pregnancy weight gain. It was noted that women gained more weight during their first pregnancy than during the subsequent pregnancies.

Abrams et al (1995) noted that parity affected the amount of weight a woman gained during the second and third trimester. Dawes and Grudzinskas (1991) reported

that primi-gravid women gained more weight after the $37^{\text {th }}$ week than parous women. These reports agree with the result of this study.

The independent variables mothers' BMI, fathers' BMI and parity, in the multiple regression model in this study (Table 7 ), explained $22.7 \%\left(R^{2}=0.227\right.$ ) of the variance in pregnancy weight gain. This is much higher than the findings of Abram et al (1995) 
whose results indicated a value of $R^{2}=0.060$ and Dawes and Grudzinskas(1991) whose findings indicated $R^{2}=0.090$.

\section{Subject Age and Pregnancy Weight Gain}

The age of the participants was not found to be significantly associated with pregnancy weight gain. This result contradicts the findings of Siega-Riz and Adair (1993). Their study noted that age was negatively related to overall pregnancy weight gain. The study $(n=1367)$ found that women over 35 years had significant negative effects on total weight gain.

On the other hand Dawes and Grudzinskas (1991) reported that maternal weight gain was less in women who were younger (less than 20 years) than women who were older (more than 25 years). This study had a sample size of $n=1145$.

The reason for this discrepancy might be due to the sample size. Both the studies that found significance between age and pregnancy weight gain had very large sample size. The sample size of this study was not large enough to determine the association between age and pregnancy weight gain.

\section{Gestation Days, Mothers' BMI and Newborn Weight}

In the present study gestation days and mothers' pre-pregnancy BMI was noted to be significant contributing factors in explaining the variance in the birth weight of the newborns. Johnson et al (1992) has reported similar results. Their study concluded that increased maternal pre-pregnancy BMI and maternal gestational weight gain were associated with increased risk of fetal macrosomia and decreased frequencies of low birth weight. 
Maternal thinness $(\mathrm{BMl}<19)$ was found to marginally increase the risk of pre-term delivery. It was also associated with small for gestational age and low birth weight babies, whereas, obesity was associated with large for gestational age babies (Lumme and Rantakallio, 1995).

Cnattingius et al (1998) noted that higher maternal weight before pregnancy increases the risk of late fetal death, although it protects against the delivery of small for gestational age infant. 


\section{CHAPTER 6}

\section{CONCLUSION}

The findings of this study indicate that there is a linear association between fathers' BMI and pregnancy weight gain and a curvilinear relationship between mothers' pre-pregnancy BMI and pregnancy weight gain. The prediction equation developed for weight gain may have practical application for developing strategies during pregnancy. 


\section{BIBLIOGRAPHY}

Abrams, B., Carmichael, S., Selvin, S. (1995). Factors associated with maternal weight gain during pregnancy. Obstet Gynecol . 86:170-176.

Abrams, B.F, Laros, R.K. (1986). Pre-pregnancy weight, weight gain and birth weight. Am.J.Obstet.Gynecol. 154: 503-509.

Abrams, B., Newman, V., Key, T., Parker, J. (1989). Maternal weight gain and pre term delivery. Obstet Gynecol. 74:577-583.

Abrams, B., Parker, J.D. (1990). Maternal weight gain in women with good pregnancy outcome. Obstet Gynecol. 76:1-7.

Albrecht, S.L., Miller, M.K. (1994). Assessing the importance of family structure in understanding birth outcomes. J. Fam \& Mar. 56:987-204.

American College Of Obstetricians and Gynecologists, American Dietetic Association. Assessment of maternal nutrition. Chicago: American College of Obstetricians and Gynecologists, 1978.

Ary, D., Jacobs, L., Razavieh, A. (1996). Introduction to Research in Education. New York: Harcourt Brace Publishers.

Bergmann, M.M., Flagg, E.W., Miracle-McMahill, H.L., Boeing, H. (1997).

Energy intake and net weight gain in pregnant women according to body mass index (BMI) Status. International Journal of Obesity, 21,1010-1017.

Carey, B., Weiss, R. (1992). Breast-feeding: Dads' influence. Health. 6:14-16.

Carmichael, S., Abrams, B., Selvin, S. The pattern of maternal weight gain in good pregnancy outcomes. Am J Public Health. 87:1984-1988. 
Cnattingius, S., Bergstrom, R., Lipworth, L., Kramer, M.S. (1998). Pre-pregnancy

weight and the risk of adverse pregnancy outcomes. New Eng.J Med. 338: 147152.

Dawes, M.G., Grudzinskas, J.G. (1991). Patterns of maternal weight gain In pregnancy. Br J Obstet Gynaecol. 98: 195-201.

Eastman, N.J., and E. Jackson. (1968). Weight relationships in pregnancy. I.

The bearing of maternal weight gain and pre-pregnancy weight on birth weight in full term pregnancies. Obstet. Gynecol . 23: 1003-1025.

Eberstein, I., Hummet, R.A., Nam, C.B. (1990). Sociodemographic influences on infant mortality: Direct and indirect effects. Paper presented at the annual meeting of the American Sociological Association, Washington, DC.

Gall, M.D., Borg, W.R., Gal I, J.P. (1996).Educational Research: An Introduction. $6^{\text {th }}$ Edition. New York. Longman Publishers.

Gee, S.C., Lee, E.S., Forthofer, R.N. (1976). Ethnic differentials in neonatal and postneonatal mortality: A birth cohort analysis by a binary variable multiple regression method. Social Biology. 23:317-325.

Hediger, M.L., Scholl, T.O., Belsky, D.H., Ances, I.G., Salmon, R.W. (1989).

Patterns of weight gain in adolescent pregnancy. Obstet Gynecol.74: 6-12.

Humphreys, R.C. (1954). An analysis of the maternal and foetal weight factors in normal pregnancy. J. Obstet. Gynaecol. Br. Commonw. 61:764-771.

Hytten, F.E, Leitch, I.(1971). The Physiology of Human Pregnancy, $2^{\text {nd }}$ Ed. Blackwell Scientific Publications, Oxford 599pp. 
IOM, Institute of Medicine.(1990). Subcommittee on Nutritional Status and Weight Gain During Pregnancy and Lactation. Washington: National Academy Press.

Johnston, C.S., Kandell, L.A. (1992). Prepregnancy weight and rate of maternal weight gain in adolescents and young adults. J Am Diet Assoc. 92:1515-1517.

Johnston, E.M. (1991). Weight changes during pregnancy and the postpartum period. Prog Food Nutr SC.15:117-157.

Johnston, J.W., Longmate, J.A., Frentzen, B. (1992). Excessive weight gain and pregnancy outcome. AmJ Obstet Gynecol. 167:353-370.

Lumme, R., Rantakallio, P. (1995). Pre-pregnancy weight and its relation to pregnancy outcome. J Obstet Gynecol. 15:69-75

Miller, H.C., Merritt, T.A. (1979). Fetal growth in humans. Year Book Medical Publishers, Chicago. 180pp

NRC, National Research Council (1970). Maternal nutrition and the course of pregnancy. Report of the committee on maternal nutrition. Food and Nutrition Board. National Academy of Sciences, Washington, DC.

Nutrition Software (1993). Nutritionist IV for DOS 3.5, Version 3.0 N-Squared Computing. Oregon: Salem.

Ratner, R.E., Hammer, L.H., Dlsada, N.B. (1990). Effects of gestational weight gain in morbidly obese women:II: Fetal Morbidity. Am J Perinatol . 7:295-299.

Siega-Riz, A.M., Adair, L.S. (1993). Biological determinants of pregnancy weight gain in a filipino population. Am J Clin Nutr. 57:365-372.

Siega-Riz, A.M., Adair, L.S., Hobel, C.J. (1994). Instute of medicine maternal 
weight gain recommendations and pregnancy outcome in a predominantly hispanic population. Obstet Gynecol. 84:565-573.

Thomson, A.M., Billewicz, W.Z. (1957). Clinical significance of weight trends during pregnancy. Br. Med. J. 1:243-247.

Williams, S.R., \& Worthington-Roberts,B.S. 1996). Nutrition throughout the Life cycle. $\left(3^{\text {rd }}\right.$ ed). St. Louis, Mo: Mosby.

Witwer, M. (1990). Low rate of weight gain late in pregnancy may signal premature birth. Family Planning Perspective. 22:92-94. 
APPENDIX A 


\section{The Special Supplemental Food Program For Women, Infants and Children (WIC)}

1. Sponsored by the Food and Nutrition Service of the U.S. Department of Agriculture

2. Originally authorized in 1972

3. Target population: Pregnant and postpartum women up to 6 months after delivery if not breast feeding and up to 12 months if breast feeding; infants; children up to 5 years of age

4. Eligibility criteria: nutritionally at risk and members of low income families

5. Program administered by the state health departments

6. Regulations require that WIC agencies offer nutrition education and that appropriate health services be available directly or by referral 


\section{APPENDIX B}




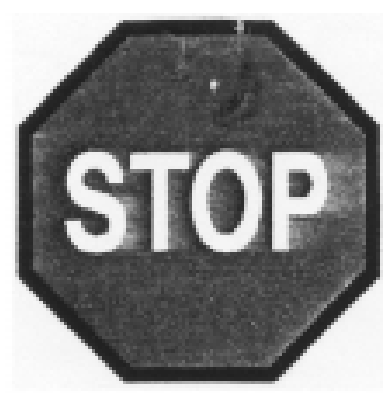

\section{ATTENTION! PREGNANT MOTHERS DO YOU NEED EXTRA CASH?}

The Division of Family Resources at West Virginia University is conducting a study which will look at many factors that may have an impact on the health of your baby.

The study involves interviewing you and obtaining information about your diet.

Pregnant women who VOLUNTEER to participate in the study will be paid for their participation. wat west watans

All information will be kept confidential.

If interested, please contact Dr. Hazel Hiza at (304) 293-3402 ext. 1768. 
APPENDIX C 


\title{
CONSENT FORM
}

\author{
Factors Affecting Perinatal, Maternal, \\ Nutritional Status, Healthcare and Pregnancy Outcomes
}

Introduction. I, have been asked to participate in the study being conducted by $\mathrm{Dr}$. Hazel Bourne Hiza and Dr. Virgil Norton at West Virginia University. This study is funded by the United States Department of Agriculture (USDA) and the West Virginia Agricultural and Forestry Experiment Stations, West Virginia University, College of Agriculture, Forestry and Consumer Sciences.

Purpose(s) of the study. This study will be performed in my home or at the WIC site. I will meet privately with the research assistant. I will be interviewed to answer several lists of written questions. The questions will be related to how I eat during pregnancy, my food shopping practices, my maternal health, prenatal care and a variety of questions that could have a positive or negative impact on my baby's health. I will be asked to take one blood test by a trained lab technician to determine the level of certain nutrients in my blood. The quantity of blood to be taken from me for the one time blood draw will be about one tablespoon. Additionally, I will be asked to provide information from my prenatal record and my baby's birth certificate. I do not have to answer all of the questions or provide any of the information from my prenatal records or my baby's birth certificate or take a blood test. I understand that it will take me about two hours to answer the interview questions and about ten minutes for the blood test. I have been given the opportunity to examine these questionnaires and handouts.

Risks. I understand that I may experience slight discomfort, bruising or bleeding during the one time blood draw by the trained lab technician. Some questions are of a sensitive nature, e.g. illicit drug use, hence I may feel uncomfortable when responding to these questions.

Benefits. I understand that there will be no direct benefit to me but what they learn from this study may help pregnant women and infants in West Virginia and other states.

Financial Considerations. If I join the study in the third trimester of my pregnancy I understand that I will receive $\$ 35$ in cash after I have completed the study. If I join the study in my first or second trimester of pregnancy I will receive $\$ 50$ in cash after I have completed the study.

Contact Persons. For more information about this research, I can contact at or her supervisor, Dr. Hazel Bourne Hiza at 304-293-3402 ext. 1768. For information regarding my child's rights as a research subject, I may contact the Executive Secretary of the Institutional Review Board at 304-2937073.

Confidentiality. I understand that any information obtained as a result of my participation in this research will be kept as confidential as legally possible. I understand that these research records, just like hospital records, may be subpoenaed by court order or may be inspected by federal regulatory authorities. However, I also know that such an occurrence is highly unlikely given the nature of this research. If any publications result from this research, neither my name nor any information from which I might be identified will be published.

Voluntary Participation. Participation in this study is voluntary. I understand that I may withdraw from this study at any time. Refusal to participate or withdraw will involve no penalty or loss of medical benefits or negative consequences for me. I have been given the opportunity to ask questions about the research, and I have received answers concerning areas I do not understand. Upon signing this form, I will receive a copy.

I willingly consent to participate in this study.

Signature of (Participant)

Signature of Investigator or

Date

Investigator's Representative 


\section{ASSENT FORM}

Factors Affecting Perinatal, Maternal, Nutritional Status, Healthcare and Pregnancy Outcomes

Introduction. study, which has been explained to me by have been asked to be in this research this project. This study is funded by the United States Department of Agriculture (USDA) and the West Virginia Agriculture and Forestry Experiment Stations, West Virginia Univesity, College of Agriculture, Forestry and Consumer Sciences.

Purpose(s) of the study. I have been told that the purpose of this study is to learn more about the many factors that may have an impact on my baby's health.

Description of Procedure. This study will be performed in my home or at the WIC site. I will meet privately with the research assistant. I will be interviewed to answer several lists of written questions. The questions will be related to how to eat during pregnancy, my food shopping practices, my maternal health, prenatal care, and a variety of questions that could have a positive or a negative impact on my baby's health. I will also be asked to take one blood test by a trained lab technician to determine the level of certain nutrients in my blood. The quantity of blood to be taken from me for the one time blood draw will be about one tablespoon. Additionally, I will be asked to provide information from my prenatal record and my baby's birth certificate. I do not have to answer all of the questions or provide all of the information from my prenatal record or my baby's birth certificate or take a blood test. I understand that it will take me about two hours to answer the interview questions and about ten minutes for the blood test. I will be given the opportunity to view the questionnaires before signing the consent forms.

Risks. I understand that I may experience slight discomfort, bruising or bleeding during the one time blood draw by the trained lab technician. I may feel uncomfortable when responding to some of the questions.

Benefits. I understand that what they learn from this study may help pregnant women and infants in West Virginia and other states.

Financial Considerations. If I join the study during my last trimester of pregnancy I understand that I will receive $\$ 35$ in cash after I complete the study. If I join the study when I am in my first or second trimester of pregnancy I will receive $\$ 50$ in cash after I complete the study. 
Confidentiality. I have been promised that anything they learn about me in this study will be kept as secret as possible. Any materials that I complete, my interview and my lab results will be given an identification number instead of my name. Only the research investigator, Dr. Hazel Bourne Hiza, and her assistants will know that I was in the study.

Voluntary Participation. I have been told that I do not have to do this study. No one will be upset with me if I refuse to do this, or quit after I have started. I have been allowed to ask questions about the research and all of my questions were answered. I will receive a copy of this form after I sign it.

I willingly agree to participate in this study.

Signature of Participant Date

Signature of Investigator or Date Investigator's Representative 


\title{
PARENTAL OR GUARDIAN CONSENT FORM
}

\author{
Factors Affecting Perinatal, Maternal, \\ Nutritional Status, Healthcare and Pregnancy Outcomes
}

Introduction. I, have been asked to allow my adolescent to participate in this study being conducted by Dr. Hazel Bourne Hiza and Dr. Virgil Norton at West Virginia University. This study is funded by the United States Department of Agriculture (USDA) and the West Virginia Agricultural and Forestry Experiment Stations, West Virginia University, College of Agriculture, Forestry and Consumer Sciences.

Purpose(s) of the study. This study will be performed in my home or at the WIC site. My adolescent will meet privately with the research assistant. She will be interviewed to answer several lists of written questions. The questions will be related to how she eats during pregnancy, her food shopping practices, her maternal health, prenatal care and a variety of questions that could have a positive or negative impact on her baby's health. She will be asked to take one blood test by a trained lab technician to determine the level of certain nutrients in her blood. The quantity of blood to be taken from my daughter for the one time blood draw will be about one tablespoon. Additionally, my adolescent will be asked to provide information from her personal prenatal records and her baby's birth certificate. She does not have to answer any of the questions or provide any of the information from her prenatal records or her baby's birth certificate or take a blood test. I understand that it will take her about two hours to answer the interview questions and about ten minutes for the blood test. I have been given the opportunity to examine these questionnaires and handouts. I agree not to examine my adolescent's responses to the questions, to protect her right to confidentiality.

Risks. I understand that my adolescent may experience slight discomfort, bruising or bleeding during the one time blood draw by the trained lab technician. Some questions are of a sensitive nature, e.g. illicit drug use, hence she may feel uncomfortable when responding to these questions.

Benefits. I understand that there will be no direct benefit to me but what they learn from this study may help pregnant women and infants in West Virginia and other states.

Financial Considerations. If she joins the study in the third trimester of her pregnancy I understand that my adolescent will receive \$35 in cash after she has completed the study. If she joins the study in her first or second trimester of pregnancy she will receive $\$ 50$ in cash after she has completed the study.

Contact Persons. For more information about this research, I can contact at $\_$or her supervisor, Dr. Hazel Bourne Hiza at 304-293-3402 ext. 1768 . For information regarding my adolescent's rights as a research subject, I may contact the Executive Secretary of the Institutional Review Board at 304-293-7073. 
Confidentiality. I understand that any information obtained as a result of my adolescent's participation in this research will be kept as confidential as legally possible. I understand that these research records, just like hospital records, may be subpoenaed by court order or may be inspected by federal regulatory authorities. However, I also know that such an occurrence is highly unlikely given the nature of this research. If any publications result from this research, neither my name nor that of my adolescent nor any information from which we might be identified will be published.

Voluntary Participation. Participation in this study is voluntary. I understand that I may withdraw my adolescent from this study at any time. Refusal to participate or withdraw will involve no penalty or loss of medical benefits or negative consequences for me or my adolescent. I have been given the opportunity to ask questions about the research, and I have received answers concerning areas I do not understand. Upon signing this form, I will receive a copy.

I willingly consent to my adolescent's participation in this study.

Signature of Parent or Guardian Date

Signature of Investigator or Date Investigator's Representative 


\section{APPENDIX D}


NAME

EXPECTED DATE OF DELIVERY

How much did you weigh at each prenatal visit?

What was your blood pressure at each prenatal visit?

\begin{tabular}{|c|c|c|c|}
\hline Date & Prenatal visit & $\begin{array}{c}\text { Weight } \\
\text { Lbs. and Ozs. }\end{array}$ & $\begin{array}{l}\text { Blood Pressure } \\
\text { Sys/Dia }\end{array}$ \\
\hline \multicolumn{4}{|c|}{ \# 1} \\
\hline \multicolumn{4}{|c|}{$\# 2$} \\
\hline \multicolumn{4}{|c|}{$\# 3$} \\
\hline \multicolumn{4}{|c|}{$\# 4$} \\
\hline \multicolumn{4}{|c|}{$\# 5$} \\
\hline \multicolumn{4}{|c|}{$\# 6$} \\
\hline \multicolumn{4}{|c|}{$\# 7$} \\
\hline \multicolumn{4}{|c|}{ \# 8} \\
\hline \multicolumn{4}{|c|}{$\# 9$} \\
\hline \multicolumn{4}{|c|}{$\# 10$} \\
\hline \multicolumn{4}{|c|}{$\# 11$} \\
\hline \multicolumn{4}{|c|}{$\# 12$} \\
\hline \multicolumn{4}{|c|}{$\# 13$} \\
\hline \multicolumn{4}{|c|}{$\# 14$} \\
\hline \multicolumn{4}{|c|}{$\# 15$} \\
\hline \multicolumn{4}{|c|}{$\# 16$} \\
\hline \multicolumn{4}{|c|}{$\# 17$} \\
\hline \multicolumn{4}{|c|}{$\# 18$} \\
\hline \multicolumn{4}{|c|}{$\# 19$} \\
\hline \multicolumn{4}{|c|}{ \#20 } \\
\hline \multicolumn{4}{|c|}{$\# 21$} \\
\hline \multicolumn{4}{|c|}{ \#22 } \\
\hline & $\# 23$ & & \\
\hline
\end{tabular}


APPENDIX E 
Factors Affecting Perinatal, Maternal, Nutritional Status, Healthcare and Pregnancy Outcomes

\section{4-Hour Food Recall (Mother)}

ID\#

WIC

Please record the type and amounts of all foods and drinks consumed from the time you get up in the morning until you go to bed at night. (example: $2 \%$ milk, 1 cup)

Morning:

Midmorning:

Noon:

Afternoon:

Evening:

Before Bed:

*You must obtain permission from the principle investigator, Dr. Hazel B. Hiza, before you can use this questionnaire. Please contact the PI at 202-606-4830 or 301-935-2723. 


\section{Rini Banerji}

3780 Max Place, Apt. 203, Boynton Beach, FL 33436

Phone: (561)742-5966, E-mail: dietdoc@ @otmail.com

\section{Education}

Master of Science in Nutrition, December 1999, West Virginia University. GPA 4.0

Bachelor of Science in Nutrition, December 1997, West Virginia University. GPA 3.99

\section{Work Experience}

1999 Dietetic Internship, West Virginia University, Morgantown, WV

1998 - 1999 Graduate Assistant, Extension Services - Nutrition, West Virginia University, Morgantown, WV.

1996 - 1997 Research Assistant, Division of Family \& Consumer Sciences. West Virginia University. Morgantown, WV.

1993 - 1996 Food Service Assistant, Mountainlair Bakery, West Virginia University, Morgantown, WV.

\section{Awards \& Honors}

WVU Foundation Outstanding Senior.

1997 Outstanding Senior Award, Gamma Sigma Delta

1997 Certificate for Outstanding Scholarship \& Leadership, College of Agriculture \& Forestry, West Virginia University.

1997 Outstanding Senior Academic Achievement, Human Nutrition and Foods Department, College of Agriculture \& Forestry, West Virginia University.

1997 Member, Golden Key National Honor Society.

1997 Member, Phi Upsilon Omicron.

1997 President's List, West Virginia University.

$1996 \quad$ President's List, West Virginia University.

1996 Recognition for Scholastic Achievement - Junior with Highest GPA. Human Nutrition and Foods Department, College of Agriculture \& Forestry, West Virginia University.

Member, Phi Kappa Phi.

References on request. 